\title{
Effects of habitat type on bird nesting in the desert grasslands of central Mexico: conservation implications
}

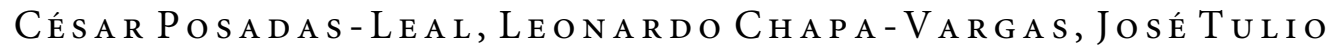 \\ ARREDONDO-MORENO and ELISABETH HUBER-SANNWALD
}

\begin{abstract}
Populations of North American grassland birds have suffered drastic declines. The causes of these declines are only partially understood and may vary among regions. During the 2004 and 2005 breeding seasons we recorded survival information from 220 nests of four bird species in nine study sites representing three habitat types of the desert grasslands of central Mexico, where grassland birds had not yet been studied. We predicted that land-use change from shortgrass steppe to heavily grazed savannahtype grasslands and agriculture would negatively affect nesting success, number of fledglings and nest abundance. We also examined temporal effects on reproductive success. We found some evidence that nest survival of savannah sparrows Passerculus sandwichensis, loggerhead shrikes Lanius ludovicianus and white-winged doves Zenaida asiatica varied with date, and that nest survival of the dove was lowest in agricultural sites. However, confidence intervals were large, suggesting that other variables were also important. Whereas white-winged dove nests were notably more abundant in agricultural areas compared to the other habitat types, western meadowlark Sturnella neglecta nests were not found in agricultural areas. Ploughing caused the largest proportion of nest failures in agricultural areas and, on average, all species fledged fewer young per nest in agricultural areas. Therefore, minimizing agriculture and adjusting harvest times could enhance conservation of grassland-nesting birds in central Mexico. Our study also suggests that inter-annual variation in rainfall can change the onset of nesting by at least 2 months.
\end{abstract}

Keywords Chihuahua desert, grassland birds, habitat types, Mexico, nest abundance, nest productivity, nest survival

\section{Introduction}

D opulations of many North American grassland birds are declining (Winter \& Faaborg, 1999; Winter et al.,

César Posadas-Leal, Leonardo Chapa-Vargas (Corresponding author), José Tulio Arredondo-Moreno and Elisabeth HuberSAnnwald División de Ciencias Ambientales, Instituto Potosino de Investigación Científica y Tecnológica A.C., Camino a la Presa San José 2055, Col Lomas 4ta Sección, San Luis Potosí, C.P. 78126 S.L.P., Mexico. E-mail lchapa@ipicyt.edu.mx

Received 13 January 2009. Revision requested 14 April 2009.

Accepted 28 May 2009.
2000; Herkert et al., 2003). Habitat loss and degradation because of encroachment of woody vegetation (Davis, 2004), cattle grazing and conversion of grasslands to agriculture are contributing to these declines (Herkert, 1995; Peterjohn \& Sauer, 1999; Vickery et al., 1999). The effects of land-cover change on nest survival in grassland habitats are variable depending on bird species, type of grassland and degree of degradation (Fondell \& Ball, 2004; Pavel, 2004; Shochat et al., 2005a,b).

The least studied grassland bird communities and populations are those that breed in the desert grassland (sensu Rzedowski, 1975; McClaran, 1995) of the Chihuahuan Desert ecoregion of northern and central Mexico and the southeastern United States (reviewed in Askins et al., 2007). Over the last 50 years grassland ecosystems in central Mexico have undergone severe transformations for intensive livestock grazing, which includes shrub encroachment, and from conversion to rain-fed agriculture (agriculture based on summer precipitation only). This process of land-use change has created a landscape of three main land-cover types: natural, grass-dominated grasslands (shortgrass steppes), savannah-type grasslands with a grass and shrub layer, and agricultural lands with strips of native vegetation. Several declining bird species breed in these habitats and there is increasing evidence that land-use and cover changes have diminished available habitat for grassland birds and thus contributed to their decline (Askins et al., 2007).

Studies in similar types of modified grasslands in North America have shown that changes in vegetation structure driven by shrub encroachment (Davis, 2004), cattle grazing and agricultural tillaging negatively influence nest site availability (Kantrud \& Kologiski, 1982; Saab et al., 1995) and nest abundance, and increase nest predation rates (Johnson \& Temple, 1990; Riley et al., 1992; Fondell \& Ball, 2004). Therefore, overall reproductive success of birds may differ substantially between habitat types (Rosenstock \& Van Riper, 2001; Shochat et al., 2005a,b). Most of the natural desert grassland in the Chihuahua desert is not protected (Askins et al., 2007) and strategies to preserve natural resources outside reserves are required. Knowledge of how the reproductive ecology of grassland birds varies among habitat types will aid the development of suitable management strategies to protect grassland bird populations in nature reserves, private lands and communal lands (ejidos) throughout northern and central Mexico. 
The main objective of our study was to examine nest abundance, survival of nests, number of young fledged per nest attempt, and number of young fledged per successful nest of several bird species in three habitat types in the Mexican desert grassland: shortgrass steppe, savannah-type grasslands and rain-fed agriculture on former shortgrass steppe. As survival of nests may fluctuate substantially and non-linearly with age of the nest and date (Grant et al., 2005) we also examined the influence of temporal effects (date and nest age) on reproductive success. Our predictions were that land-use change from shortgrass steppe to heavily grazed savannah-type grasslands and to agriculture would negatively affect nesting success, number of fledglings and nest abundance.

\section{Study area}

Our study was conducted in the sub-province of Llanos de Ojuelos, Jalisco, Mexico (Fig. 1) where shortgrass steppe, savannah-type grasslands, and rain-fed agriculture on former shortgrass steppe are dominant at c. 2,100 m altitude. For each habitat type we randomly selected three sites with similar habitat characteristics. The shortgrass steppe sites are grazed by cattle Bos taurus year-round at a stocking rate of $0.125 \mathrm{ha}^{-1}$. These sites are characterized by the short-statured grass species Bouteloua gracilis, Bouteloua scorpioides, Bouteloua hirsuta, Boutelou simplex,
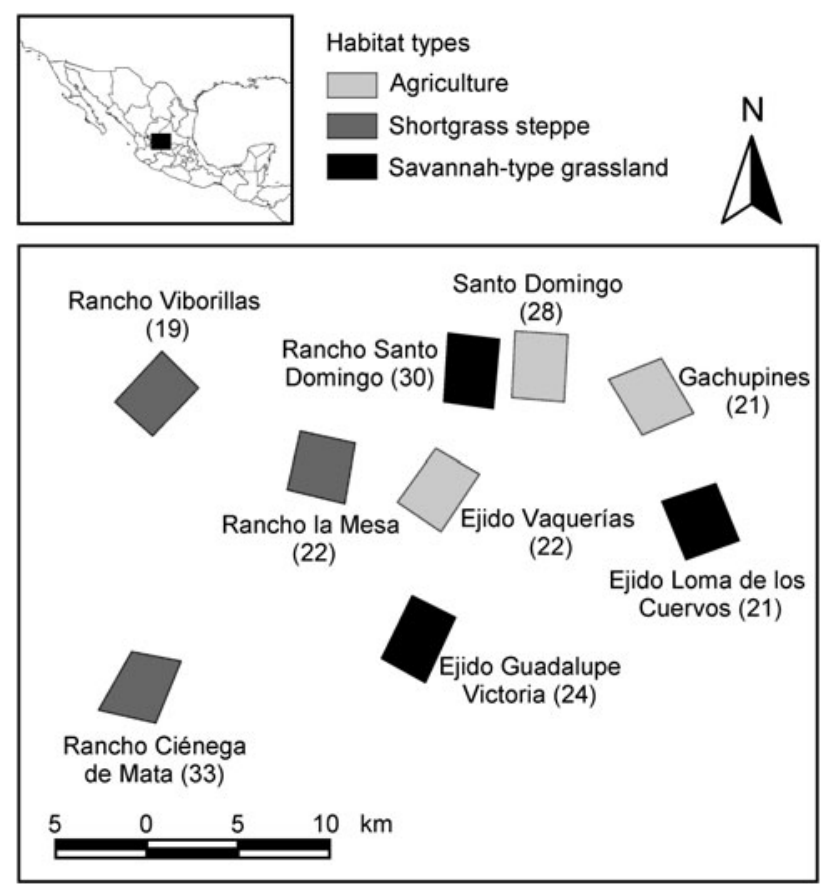

FIG. 1 Locations of the nine study sites, with three each of the three habitat types (agriculture, shortgrass steppe and savannahtype grasslands). The shaded rectangle on the inset shows the location of the study area in the sub-province of Llanos de Ojuelos, Jalisco, Mexico. Numbers in parentheses indicate number of nests found at each study site.
Aristida divaricata, Microchloa kuntii, Buchloë dactyloides and Muhlenbergia rigida, with isolated sub-shrubs, shrubs and trees. The savannah-type grassland sites are also grazed throughout the year but at higher stocking rates of $0.5 \mathrm{ha}^{-1}$. These sites are characterized by an open layer of grasses (B. gracilis, B. scorpioides and A. divaricata), and an open layer of shrubs and trees, including Acacia schaffneri, Yucca decipiens, Mimosa biuncifera, Dalea bicolor, Brickellia spinulosa, Opuntia robusta, Opuntia leucothicha, Opuntia imbricata and Opuntia streptacantha. The agricultural sites are usually covered (70\%) by annual crops (beans, barley and corn) from June to September. During the rest of the year most crop fields are uncovered or interspersed with grasses, sub-shrubs, shrubs and trees in similar proportions.

For the three habitat types we selected similar-sized and similar-shaped, relatively unfragmented sites $(>340$ ha; Fig. 1) to avoid potential confounding effects of different fragmentation patterns at different sites. Because edge effects may extend as far as $500 \mathrm{~m}$ (Davis et al., 2006; Grant et al., 2006) we only searched for nests in areas $>1,000 \mathrm{~m}$ from habitat edges.

\section{Methods}

During the nesting period in March-August 2004 and 2005 we searched for nests at each site by following adult birds and by dragging a 50-m long rope, held by a person at each end, through the vegetation to flush adult birds from their nests (Ralph \& Scott, 1981). We monitored nests of loggerhead shrike Lanius ludovicianus, savannah sparrow Passerculus sandwichensis, white-winged dove Zenaida asiatica and western meadowlark Sturnella neglecta. The savannah sparrow and western meadowlark are declining across at least $50 \%$ of their breeding distribution in the USA and Canada. The loggerhead shrike is declining through most of its breeding distribution in the same region (Sauer et al., 2008) and has been identified as a species of conservation concern (US Fish and Wildlife Service, 2008). We included the white-winged dove as a comparison species as its populations are increasing (Sauer et al., 2008) across most of its breeding range in the USA. Each nest was labelled with a tag, attached to a nearby plant, for easy relocation, and georeferenced with a global positioning system (GPS). We examined each nest every 3-4 days from the day it was found until it failed or fledged young. We used a mirror attached to a pole to monitor nests at heights greater than $2 \mathrm{~m}$ above ground (Parker, 1972). Indications of successful fledging events were nests with nestlings close to fledging on visit $t$, and empty nests, fresh droppings and/ or activity of juveniles and adults near nests at consecutive visits $(t+1, t+2$, etc.). Indications of nest failure were shell fragments, pierced eggs and/or destroyed nests (Martin \& Geupel, 1993; Manolis et al., 2000). 
For all species we calculated the mean, standard error and range of number of eggs, incubation days and brooding days per nest. To calculate these variables we only used nests whose complete clutch size, incubation and/or brooding periods were known. To estimate clutch size we only used nests that were found during the incubation period and we assumed that the complete clutch size was the largest number of eggs ever recorded in the nest. This assumption is reasonable because we never recorded partial clutch losses. For each species we recorded the number of nests found in each habitat type and the substrate (grass, forb, shrub, cacti and/or tree) on which nests were found. For each species we present clutch size, number of incubation days, brooding days, nests in each habitat type (nest abundance), and nesting substrates.

To analyse nest survival data we used the NLMIXED procedure in SAS (SAS Institute, 2005) for mixed models (Rotella et al., 2007) to fit logistic exposure models (Shaffer, 2004; Rotella et al., 2007) to the data. We conducted separate analyses for each species. We used Akaike's Information Criterion corrected for small sample sizes (AICc) and Akaike weights $\left(\omega_{\mathrm{i}}\right.$; Burnham \& Anderson, 2002) to evaluate support for competing a priori hypotheses related to factors influencing survival of nests in the different habitat types. To calculate AICc for nest survival we used the effective sample size (the sum of the total number of days that all nests were known to have survived plus the number of intervals between visits to nests that ended in failure; Rotella et al., 2004). Before evaluating the influence of habitat type on nest survival we assessed time effects. The six a priori time-related, nest survival models were: (1) a constant survival model, ( 2 \& 3 ) linear effects of age (the age of a nest in days) and date (the Julian date at the time in which the nest was visited; e.g. day 1 refers to the date when the first nest became active), (4 \& 5) quadratic effects of age and date, and (6) a global model with all parameters from the previous models. Quadratic effects included both linear (x) and quadratic $\left(\mathrm{x}^{2}\right)$ effects (Grant et al., 2005). These polynomial models allowed us to explore potential variation within the nesting cycle related to differences among nesting stages, and variation within the breeding season (Grant et al., 2005).

We then conducted an analysis comparing time-specific effects with habitat type effects. We constructed five a priori nest survival models: (1) a constant survival model, (2) the best-supported time effects model, (3) a habitat type effects model, (4) an additive model incorporating time effects and habitat type, and (5) a global model that included time effects, habitat type and the interactions of these two effects. The global model of nest survival was used to assess model fit (Burnham \& Anderson, 2002) using the Hosmer \& Lemeshow (2000) goodness-of-fit test. We then calculated model-averaged weighted parameter estimates and their associated standard errors using Akaike weights (Burnham \&
Anderson, 2002; Shaffer, 2004). Weighted parameter estimates and standard errors were used to calculate oddratios, their standard error, and confidence intervals. We only interpreted variables if the confidence intervals of the odd-ratios did not include 1, as recommended by Hosmer \& Lemeshow (2000).

\section{Results}

We collected nest survival information for 220 nests: 47 of savannah sparrow, 62 of loggerhead shrike, 75 of whitewinged dove and 36 of western meadowlark (Table 1). The number of nests found per site was 19-33 (Fig. 1). Whitewinged doves were common in all study sites, with the highest nest abundance per site each year in agricultural sites (mean $=9.25 \pm \mathrm{SE} 1.03)$ and a lower nest abundance in savannah $($ mean $=4.0 \pm \mathrm{SE} 1.05)$ and grassland sites $($ mean $=$

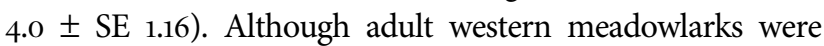
common in all three habitat types, nests of this species were not found in agricultural sites (Table 1). The number of nests of both loggerhead shrike and savannah sparrow were similar between habitat types (Table 1). Mean numbers of fledglings per nest of savannah sparrow, loggerhead shrike and whitewinged dove were fewer in agricultural sites compared to shortgrass steppes and savannah-type grassland but mean fledglings per successful nest varied little between habitat types (Table 2).

No nests were found during either the nest-building or egg-laying stages. For the shortgrass steppe and savannahtype grassland sites the primary cause of nest mortality was predation; trampling by cattle caused the failure of $<1 \%$ of all nests in these habitat types. In agricultural sites ploughing accounted for most nest failure $(78 \%)$ and predation for the remaining $22 \%$.

Akaike information criterion results indicated that the best models explaining variation in nest success in relation to time-related effects were those including the following independent effects: quadratic date effects for loggerhead shrike and savannah sparrow (loggerhead shrike: $\triangle \mathrm{AIC}=0$, $\omega_{\mathrm{i}}=0.508$; savannah sparrow: $\left.\Delta \mathrm{AIC}=0, \omega_{\mathrm{i}}=0.253\right)$, constant survival (no effects) and linear date effects for meadowlark ( $\triangle \mathrm{AIC}=0$ and $0.36, \omega_{\mathrm{i}}=0.26$ and 0.21 , respectively), and linear date effects for white-winged dove $(\triangle \mathrm{AIC}=0$, $\left.\omega_{\mathrm{i}}=0.341\right)$. When habitat type effects and time effects were analysed simultaneously, results of the Hosmer \& Lemeshow's (2000) goodness-of-fit tests indicated that model fit was reasonable for all four species $\left(\chi^{2}=0.999, \mathrm{df}=9\right.$, and $\mathrm{P}>0.05)$.

Nest survival of savannah sparrow and loggerhead shrike responded to date, increasing slightly at the beginning and decreasing at the end of the breeding season, although confidence intervals were large. Survival of white-winged dove nests varied among habitat types; it was lower for nests in agricultural sites compared to those in savannah-type 
TABLE 1 Number of nests and nesting characteristics of the four studied bird species in the three habitat types at Llanos de Ojuelos, Jalisco, Mexico (Fig. 1).

\begin{tabular}{|c|c|c|c|c|c|c|c|}
\hline \multirow[b]{2}{*}{ Species } & \multicolumn{3}{|c|}{ Nests found ${ }^{1}$} & \multirow{2}{*}{$\begin{array}{l}\text { No. of eggs } \\
\text { per nest } \pm \text { SE } \\
\text { (range) }\end{array}$} & \multirow{2}{*}{$\begin{array}{l}\text { No. of incubation } \\
\text { days } \pm \text { SE (range) }\end{array}$} & \multirow{2}{*}{$\begin{array}{l}\text { No. of brooding } \\
\text { days } \pm \text { SE (range) }\end{array}$} & \multirow{2}{*}{$\begin{array}{l}\text { Nesting } \\
\text { substrates }\end{array}$} \\
\hline & A & G & S & & & & \\
\hline $\begin{array}{l}\text { Loggerhead shrike Lanius } \\
\text { ludovicianus }\end{array}$ & 14 & 21 & 27 & $3 \pm 0.0(3-3)$ & $16.3 \pm 0.12(15-17)$ & $19.1 \pm 0.74(12-26)$ & $\mathrm{s}, \mathrm{t}$ \\
\hline $\begin{array}{l}\text { Savannah sparrow Passerculus } \\
\text { sandwichensis }\end{array}$ & 14 & 22 & 11 & $3 \pm 0.0(3-3)$ & $11.8 \pm 0.16(10-13)$ & $12.9 \pm 0.15(11-15)$ & $f, g$ \\
\hline $\begin{array}{l}\text { Western meadowlark Sturnella } \\
\text { neglecta }\end{array}$ & 0 & 19 & 17 & $2 \pm 0.0(2-2)$ & $13.9 \pm 0.18(12-15)$ & $18.6 \pm 0.84(10-25)$ & g \\
\hline $\begin{array}{l}\text { White-winged dove Zenaida } \\
\text { asiatica }\end{array}$ & 43 & 12 & 20 & $2 \pm 0.0(2-2)$ & $13.2 \pm 0.12(12-14)$ & $14.1 \pm 0.23(12-16)$ & $c, f, g$ \\
\hline
\end{tabular}

${ }^{1} \mathrm{~A}$, agricultural lands; G, shortgrass steppe; S, savannah-type grassland

${ }^{2}$ c, cacti; f, forbs; g, grass; $s$, shrubs; $t$, trees (nesting substrate for ground nests indicates the plant species with which a nest was associated)

grasslands and shortgrass steppe sites, although confidence intervals were large (Fig. 2a). Nest survival of this species also responded to date, increasing as the breeding season progressed, and confidence intervals also increased as the breeding season progressed (Fig. 2b). AIC results (Table 3) and confidence intervals of odd-ratios suggested that nest survival of western meadowlark was unrelated to the independent variables that we evaluated.

\section{Discussion}

We found only limited support for our prediction that nesting success would be lower in human-modified agricultural fields and overgrazed savannah-type grasslands compared to shortgrass steppe. Previous studies have reported low nesting success in shrub-encroached savannahtype grasslands (Rosenstock \& Van Riper, 2001; Shochat et al., 2005a,b). However, other studies have found no, or minor, effects (Bowen \& Kruse, 1993; Granfors et al., 1996; Kruse \& Bowen, 1996; Fondell \& Ball, 2004) of shrubencroached savannah-type grasslands on nest success and/ or nest densities. We did not assess the effects of several variables, including nest concealment, vegetation cover, predators and edges. Variation in these factors could have diluted any potential habitat effects and accounted for the large within-habitat variation that we recorded in whitewinged dove nest survival. Therefore we cannot eliminate the possibility that nest survival of grassland-nesting bird species in central Mexico varies between habitats without conducting studies with larger sample sizes, allowing simultaneous examination of several interacting variables. Within-habitat variation of some of these effects should be the focus of future studies.

Date effects were included in at least one of the top nest success models for every bird species analysed. We found some evidence that savannah sparrow and loggerhead shrike nest survival increased at the beginning and decreased at the end of the breeding season, although confidence intervals were large. Nesting success of whitewinged dove increased throughout the breeding season. Other studies have reported linear (not quadratic) date effects in grassland-nesting birds (Davis, 2005; Grant et al., 2005). Patterns of within-season variation in nest success may result from temporal changes in animal community composition, and thus abundances and/or activity patterns of nest predators (reviewed in Grant et al., 2005), and/or other prey species (Ackerman, 2002). Some of these variables could be responsible for the quadratic effects that we observed. Also, in contrast with findings from studies of grass-nesting birds (Davis, 2005; Grant et al., 2005; Davis et al., 2006), we did not record substantial changes in nest survival with nest age, indicating that other variables that we did not consider (see above) may have had stronger influences in our study area.

TABle 2 Mean fledglings per nest and per successful nest of the four studied bird species in the three habitat types at Llanos de Ojuelos (Fig. 1).

\begin{tabular}{lllllll}
\hline & \multicolumn{2}{l}{ Fledglings per nest $\pm \mathrm{SE}^{*}$} & \multicolumn{3}{c}{ Fledglings per successful nest $\pm \mathrm{SE}^{*}$} \\
Species & $\mathrm{A}$ & $\mathrm{G}$ & $\mathrm{S}$ & $\mathrm{A}$ & $\mathrm{G}$ & $\mathrm{S}$ \\
\hline Loggerhead shrike & $1.5 \pm 0.29$ & $2.1 \pm 0.19$ & $1.6 \pm 0.25$ & $2.0 \pm 0.21$ & $2.3 \pm 0.14$ \\
Savannah sparrow & $1.5 \pm 0.34$ & $1.8 \pm 0.16$ & $2.4 \pm 0.17$ & $2.1 \pm 0.23$ & $2.1 \pm 0.06$ & $2.5 \pm 0.12$ \\
Western meadowlark & & $1.9 \pm 0.07$ & $1.7 \pm 0.14$ & & $1.9 \pm 0.07$ & $1.8 \pm 0.10$ \\
White-winged dove & $1.4 \pm 0.15$ & $1.8 \pm 0.14$ & $1.8 \pm 0.17$ & $2.0 \pm 0.00$ & $2.0 \pm 0.00$ & $2.0 \pm 0.00$ \\
\hline
\end{tabular}

${ }^{*}$ A, agricultural lands; G, shortgrass steppe; S, savannah-type grassland 
a)

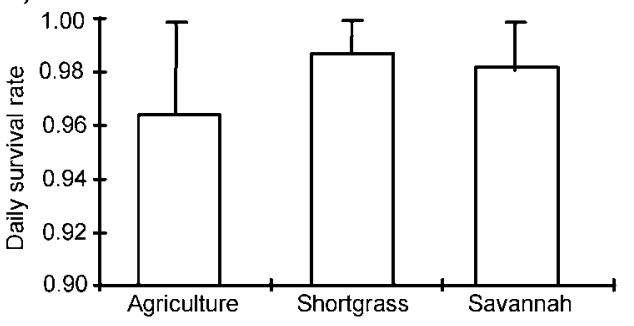

b)

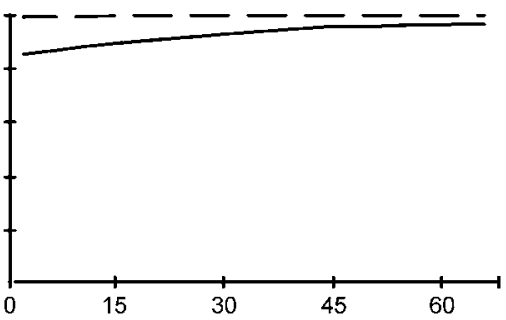

Fig. 2 Estimated mean daily nest survival rates of white-winged doves Zenaida asiatica at Llanos de Ojuelos (Fig. 1) during the 2004 and 2005 breeding seasons as a function of (a) habitat type (lower confidence limits, not shown, were 0.23 for agricultural lands, 0.38 for shortgrass steppe, and 0.52 for savannah-type grassland) and (b) date, where $1=$ first day of breeding season (lower confidence limit, not shown, ranged from 0.76 on day 9 to 0.20 on day 75). Daily survival rates were estimated from model-averaged coefficients of the best-supported logistic exposure models. Error bars and dotted lines indicate upper $95 \%$ confidence limits.

The nesting period in our study area was delayed until early June in 2004, compared to 2005 when nesting began in late March. This difference is most likely related to interannual differences in precipitation; 2004 was wetter (total annual rainfall $688 \mathrm{~mm})$, and 2005 was drier $(284 \mathrm{~mm})$ than the long-term mean annual precipitation $(350 \mathrm{~mm})$. Semiarid ecosystems such as these grasslands are dynamic, in part because of the high spatio-temporal variation in precipitation (Winter et al., 2005). The first rain event in 2005 occurred on 18 March whereas in 2004 it was in early July. Therefore it is not total annual precipitation but rather the date of the first rain that may trigger the beginning of the breeding season. Although no previous study has recorded similar correlations between nest initiation and distribution of rain events, previous research has documented that at times of severe drought nesting may terminate early, and bird densities, species richness, hatching success, number of young fledged per successful nest and nesting success are low compared to wetter years (George et al., 1992). In addition, climate change may induce early laying (reviewed in Crick, 2004).

The potential effects of the size and timing of individual precipitation events on the breeding birds of the desert grasslands of central and northern Mexico require further study. Some studies have reported important differences in nest survival between years (Davis, 2005; Davis et al., 2006), which could be related to precipitation. However, others have not recorded such differences (Grant et al., 2005). Because our study included only 2 years it was difficult to compare nest survival between years and to relate these differences to date of first rainfall. However, given the large disparity in precipitation and nesting times it is likely that precipitation affects nesting success. Long-term studies would be required to investigate this issue.

Based on our results it appears that habitat type influenced nest presence-absence and abundance patterns. Therefore, in spite of the limited support for our hypothesis of lower nesting success in human-modified habitats compared to natural grasslands, conversion to agriculture and savannah-type grasslands may influence demography by modifying the amount of habitat available. The whitewinged dove, a species that is widespread in central Mexico, showed apparent nesting preferences for agricultural lands. In contrast, western meadowlarks seemed to avoid agricultural sites for nesting. Hence, extensive conversion of shortgrass steppe to rain-fed agriculture in the desert grasslands of central and northern Mexico may have substantially increased breeding habitat for some bird species at the expense

TABLE 3 Model selection results of a priori models of nest success of the four studied bird species in Llanos de Ojuelos (Fig. 1) during the nesting seasons of 2004 and 2005. Models include the best-supported model (lowest AICc value), candidate models within two $\Delta$ AIC units of the best model, and a constant survival model. Number of parameters $(\mathrm{k})$ and AICc weights $\left(\omega_{\mathrm{i}}\right)$ for each model are provided.

\begin{tabular}{|c|c|c|c|c|c|}
\hline Species (effective sample size, no. of nests) & Model $^{\star}$ & $\mathrm{k}$ & $\mathrm{AICc}$ & $\Delta \mathrm{AICc}$ & $\omega_{\mathrm{i}}$ \\
\hline Loggerhead shrike $(725,62)$ & $\mathrm{HT}+\mathrm{TE}$ & 6 & 31.0 & 0.0 & 0.99 \\
\hline \multirow{2}{*}{ Savannah sparrow $(593,47)$} & $\mathrm{TE}$ & 3 & 108.3 & 0.0 & 0.52 \\
\hline & $\mathrm{HT}+\mathrm{TE}+\mathrm{HT}^{\star} \mathrm{TE}$ & 9 & 109.8 & 1.6 & 0.24 \\
\hline \multirow[t]{3}{*}{ Western meadowlark $(527,36)$} & $\mathrm{HT}$ & 3 & 126.8 & 0.0 & 0.33 \\
\hline & $\mathrm{HT}+\mathrm{TE}$ & 4 & 127.1 & 0.4 & 0.28 \\
\hline & $\mathrm{TE}$ & 2 & 127.6 & 0.9 & 0.22 \\
\hline \multirow[t]{3}{*}{ White-winged dove $(1,036,75)$} & Constant survival & 1 & 13.8 & 0.0 & 0.32 \\
\hline & $\mathrm{TE}$ & 2 & 14.2 & 0.4 & 0.27 \\
\hline & $\mathrm{HT}$ & 2 & 14.4 & 0.6 & 0.23 \\
\hline
\end{tabular}

${ }^{\star} \mathrm{HT}$, habitat type; TE, temporal effects 
of others and thus led to shifts in the abundance of species. In addition, ploughing contributed substantially to nest mortality and lower number of fledglings per nest in agricultural sites.

A number of management actions need to be implemented to minimize nest failures, reverse habitat decline and enhance conservation of grassland-nesting birds. These actions include implementation of limited-ploughing policies to minimize nest losses, adjusting ploughing times, establishing protected grassland corridors, and reducing land conversion to agriculture on both private and communal lands. To date these recommendations have not been followed despite the increased interest of state and federal government in the conservation of natural resources in Mexico. There are, however, various federal programmes administered by the National Forest Commission that promote conservation of biodiversity through economic incentives. Application of these programmes in combination with initiatives such as the Neotropical Migratory Bird Conservation Act (2010) could promote conservation of grassland-dependent bird populations in central Mexico.

\section{Acknowledgements}

We thank the landowners at Llanos de Ojuelos who granted us permission to conduct research on their properties. The Mexican National Council for Science and Technology (CONACYT) provided a full scholarship for the completion of CP-L's graduate studies. L. Ildrich and C. Cacho helped in the field. Five anonymous reviewers provided helpful comments that improved this article. We also thank F. Thompson III, Javier Salgado and S.K. Robinson for their comments, and J. Rotella and T. Shafer for their advice on statistical analyses.

\section{References}

ACKerman, J.T. (2002) Of mice and mallards: positive indirect effects of coexisting prey on waterfowl nest success. Oikos, 99, 469-480.

Askins, A.R., Chavez-Ramírez, F., Dale, C.B., Haas, A.C., Herkert, R.J., Knopf, L.F. \& Vickery, D.P. (2007) Conservation of grassland birds in North America: understanding ecological processes in different regions. Ornithological Monographs, 64, $1-46$.

BOWEN, B.S. \& KRUSE, A.D. (1993) Effects of grazing by upland sandpipers in south-central North Dakota. Journal of Wildlife Management, 57, 291-301.

Burnham, K.P. \& Anderson, D.R. (2002) Model Selection and Multimodel Inference: A Practical Information-Theoretic Approach. Springer Verlag, New York, USA.

Crick, H.Q.P. (2004) The impact of climate change on birds. Ibis, 146 (suppl. 1), 48-56.

D Avis, S.K. (2004) Area sensitivity in grassland passerines: effects of patch size, patch shape, and vegetation structure on bird abundance and occurrence in southern Saskatchewan. The Auk, 121, $1130-1145$.
D A VIS, S.K. (2005) Nest-site selection patterns and the influence of vegetation on nest survival of mixed-grass prairie passerines. The Condor, 107, 605-616.

Davis, S.K., Brigham, M.R., Shaffer, T.L. \& James, P.C. (2006) Mixed-grass prairie passerines exhibit weak and variable responses to patch size. The Auk, 123, 807-821.

Fondell, T.F. \& BALL, I.J. (2004) Density and success of bird nests relative to grazing on western Montana grasslands. Biological Conservation, 117, 203-213.

George, T.L., Fowler, A.C., Knight, R.L. \& McEwan, C.C. (1992) Impacts of severe drought on grassland birds in North Dakota. Ecological Applications, 2, 275-284.

Granfors, D.A., Church, K.E. \& Smith, L.M. (1996) Eastern meadowlarks nesting in rangelands and conservation reserve program fields in Kansas. Journal of Field Ornithology, 67, 222235.

Grant, T.A., Madden, E.M., Shaffer, T.L., Pietz, P.J., Berkey, G.B. \& KARDMAs, N.J. (2006) Nest survival of clay-colored and vesper sparrows in relation to woodland edge in mixed-grass prairies. Journal of Wildlife Management, 70, 691-701.

Grant, T.A., Shaffer, T.L., Madden, E.M. \& Pietz, P.J. (2005) Time-specific variation in passerine nest survival: new insights into old questions. The Auk, 122, 661-672.

Herkert, J.R. (1995) An analysis of Midwestern breeding bird population trends: 1966-1993. American Midland Naturalist, 134, $41-50$.

Herkert, J.R., Reinking, D.L., Wiedenfeld, D.A., Winter, M., Zimmerman, J.L., Jensen, W.E. et al. (2003) Effects of prairie fragmentation on the nest success of breeding birds in the midcontinental United States. Conservation Biology, 17, 587-594.

Hosmer, D.W. \& Lemeshow, S. (2000) Applied Logistic Regression, and edition. Wiley, New York, USA.

Johnson, R.G. \& Temple, S.A. (1990) Nest predation and brood parasitism of tallgrass prairie birds. Journal of Wildlife Management, 54, 106-111.

Kantrud, H.A. \& Kologiski, R.L. (1982) Effects of Soils and Grazing on Breeding Birds of Uncultivated Upland Grassland on the Northern Great Plains. Wildlife Research Report 15. US Fish and Wildlife Service, Washington, DC, USA.

Kruse, A.D. \& Bowen, B.S. (1996) Effects of grazing and burning on densities and habitats of breeding ducks in North Dakota. Journal of Wildlife Management, 60, 233-246.

Manolis, J.C., Andersen, D.E. \& Cuthbert, F.J. (2000) Uncertain nest fates in songbird studies and variation in Mayfield estimation. The Auk, 117, 615-626.

Martin, T.E. \& Geupel, G.R. (1993) Nest-monitoring plots: methods for locating nests and monitoring success. Journal of Field Ornithology, 64, 507-519.

McClaran, M.P. (1995) Desert grasslands and grasses. In The Desert Grassland (eds M.P. McClaran \& T.R. Van Devender), pp. 1-30. University of Arizona Press, Tucson, USA.

Neotropical Migratory Bird Conservation Act (2010) US Fish \& Wildlife Service, Division of Bird Habitat Conservation, Arlington, USA. Http://www.fws.gov/birdhabitat/Grants/NMBCA/index.shtm [accessed 14 April 2010].

PARKER, J.W. (1972) A mirror and a pole device for examining high nests. Bird Banding, 43, 216-218.

PAVEL, V. (2004) The impact of grazing animals on nesting success of grassland passerines in farmland and natural habitats: a field experiment. Folia Zoologica, 53, 171-178.

Peterjohn, B.G. \& Sauer, J.R. (1999) Population status of North American grassland birds from the North American Breeding Bird Survey, 1966-1996. Studies in Avian Biology, 19, 27-44. 
RALPh, C.J. \& ScOTT, J.M. (1981) Estimating numbers of terrestrial birds. Studies in Avian Biology, 6.

Riley, T.Z., Davis, C.A., Ortiz, M. \& Wisdom, M.J. (1992) Vegetative characteristics of successful and unsuccessful nests of lesser prairie chicken. Journal of Wildlife Management, 33, 122-125.

Rosenstock, S.S. \& VAN Riper, III, C. (2001) Breeding bird responses to juniper woodland expansion. Journal of Wildlife Management, 54, 226-232.

Rotella, J., Dinsmore, S.J. \& Shaffer, T.L. (2004) Modelling nest-survival data: a comparison of recently developed methods that can be implemented in MARK and SAS. Animal Biodiversity and Conservation, 27, 187-205.

Rotella, J., Taper, M., Stephens, S. \& Lindberg, M. (2007) Extending methods for modelling heterogeneity in nest-survival data using generalized mixed models. Studies in Avian Biology, 34, $34-44$.

Rzedowski, J. (1975) An ecological and phytogeographical analysis of the grasslands of Mexico. Taxon, 24, 67-80.

S Aав, V.A., Bоск, C.E., Rich, T.D. \& Doвкin, D.S. (1995) Livestock grazing effects in western North America. In Ecology and Management of Neotropical Migratory Birds: A Synthesis and Review of Critical Issues (eds T.E. Martin \& D.M. Finch), pp. 311353. Oxford University Press, New York, USA.

SAS Institute (2005) SAS/STAT User's Guide. SAS Institute Inc., Cary, USA.

Sauer, J.R., Hines, J.E. \& Fallon, J. (2008) The North American Breeding Bird Survey, Results and Analysis 1966-2007. Version 5.15.2008. USGS Patuxent Wildlife Research Center, Laurel, USA.

ShAFFer, T.L. (2004) A unified approach to analyzing nest success. The Auk, 121, 526-540.

Shochat, E., Patten, M.A., Morris, D.W., Reinking, D.L., Wolfe, D.H. \& Sherrod, S.K. (2005a) Ecological traps in isodars: effects of tallgrass prairie management on bird nest success. Oikos, 111, 159-169.
Shochat, E., Wolfe, D.H., Patten, M.A., Reinking, D.L. \& Sherrod, S.K. (2005b) Tallgrass prairie management and bird nest success along roadsides. Biological Conservation, 121, 399-407.

US Fish and Wildlife Service (2008) Birds of Conservation Concern 2008. US Fish and Wildlife Service, Division of Migratory Bird Management, Arlington, USA. Http://www.fws.gov/migratorybirds/ NewReportsPublications/SpecialTopics/BCC2008/BCC2008.pdf [accessed 18 February 2010].

Vickery, P.D., Tubaro, P.L., DaSilva, J.M.C., Peterjohn, B.G., Herkert, J.R. \& Cavalcanti, R.B. (1999) Conservation of grassland birds in the western hemisphere. Studies in Avian Biology, 19, 2-26.

Winter, M. \& Faaborg, J. (1999) Patterns of area sensitivity in grassland-nesting birds. Conservation Biology, 13, 1424-1436.

Winter, M., Johnson, D.H. \& FaAborg, J. (2000) Evidence of edge effects on multiple levels in tallgrass prairie. The Condor, 102, 256-266.

Winter, M., Johnson, D.H. \& Shaffer, J.A. (2005) Variability in vegetation effects on density and nesting success of grassland birds. Journal of Wildlife Management, 69, 185-197.

\section{Biographical sketches}

CÉSAR Posadas-Leal's main interest is the conservation of the wildlife of the grassland habitats of Central Mexico. LEONARDo CHAPA-VARGAS's research includes avian ecology, landscape ecology and wildlife ecotoxicology. José Tulio Arredondo-Moreno's research focuses on management of grassland habitats and the roles of hydrology on the functioning of arid and semi-arid ecosystems of central Mexico. Elisabeth Huber-Sannwald's research includes climate change, ecosystem services, and functioning of socio-ecological systems in arid, semi-arid and neotropical environments. 